\title{
HIGH-ORDER FINITE DIFFERENCE METHOD APPLIED TO THE SOLUTION OF THE THREE-DIMENSIONAL HEAT TRANSFER EQUATION AND TO THE STUDY OF HEAT EXCHANGERS
}

\author{
M. D. Campos ${ }^{\mathrm{a}}$, \\ and E. C. Romão \\ ${ }^{\mathrm{a}}$ Universidade Federal de Mato Grosso \\ Campus Universitário do Araguaia \\ Instituto de Ciências Exatas e da Terra \\ Av. Senador Valdon Varjão, 6390 \\ CEP 78600-000 - Barra do Garças MT Brasil \\ ${ }^{\text {b}}$ Universidade de São Paulo \\ Departamento de Ciências Básicas e \\ Ambientais \\ Estrada do Campinho, s/n, Bairro Campinho \\ CEP 12602-810 - Lorena SP Brasil \\ Received: October 29, 2014 \\ Revised: November 30, 2014 \\ Accepted: December 30, 2014
}

\begin{abstract}
Numerical experiments for four test problems are carried out to demonstrate the performance of the present method and to compare it with the others classical methods. The numerical solutions obtained are compared with the analytical solution as well as the results by other numerical schemes with emphasis on the application involving heat exchange in a rectangular channel. It can be easily seen that the proposed method is simple to implement and very efficient..
\end{abstract}

Keywords: high-order finite difference, numerical solution, heat transfer equation, heat exchangers

\section{NOMENCLATURE}



Greek symbols

$\rho \quad$ mass density

\section{INTRODUCTION}

Problems involving the advection-diffusion equation have important applications to fluid dynamics as well as many other branches of science and engineering.Because the analytical solution of these equations containing complex initial and boundary conditions are very difficult, many authors have used various numerical techniques for the solution of this equation as the finite element methods(Zienkiewicz et al., 2013), the finite volume methods(Malalasekera and Versteeg, 2007), the shooting method (Roberts and Shipman, 1972), the graphical methods (Welty et al., 2001),the modified domain decomposition method (Wazwaz, 2001), the Cole-Hopf transformation (Fletcher, 1983), the radial basis function collocation method (Islam et al., 2012), the differential transform method (Liu and Hou, 2011), the differential quadrature method (Mittal and Jiwari 2009), the Adomian decomposition method (Zhu et al., 2010) and the finite difference methods (Thomas, 1995, Morton and Mayers, 1994, Forsythe and Wasow, 2013) used in this work, are other approaches for solve the advection-diffusion equation.

In recent years, there exist a lot of studies devoted to the numerical approximation to the threedimensional advection-diffusion equations and its applications using the high-order finite difference method for solution. For example, (Dehghan, 2004) developed several second order fully explicit (unconditionally stable) and fully implicit (conditionally stable) difference schemes with constants coefficients. (Thongmoon et al., 2007) used the finite difference method to solve the threedimensional advection-diffusion that describes a mathematical model for transport of a pollutant in a street tunnel. Pollutant dispersal patterns within the tunnel were calculated and numerical results for several different pollutant source configurations were presented and discussed. (Prieto et al., 2011) used the application of the generalized finite difference method to solve the advection-diffusion equation by the explicit method and studied the convergence of 
the method and the truncation error over irregular grids. The example presented numerical example shows that a decrease in the value of the time step, always below the stability limits, leads to a decrease in the global error. (Ge et al., 2013) developed an exponential high order compact alternating direction implicit method with fourth-order in space, second order in time and unconditionally stable and solved three numerical problems to demonstrate the high accuracy and efficiency and to show its superiority over the classical Douglas-Gunn ADI scheme and the Karaa's high order ADI scheme.

Among the range of applications, simulations of rectangular cooling channels, such as happens in cold storage, have often been discussed in recent works (Smale et al., 2006; Hao and Ju, 2011) and will be operated in the Application 4 of this work.

\section{GOVERNING EQUATIONS: TEMPORAL AND SPATIAL DISCRETIZATION}

A In this work, we propose a solution by the high-order finite difference method for the threedimensional advection-diffusion equation which is given by.

$$
\begin{aligned}
& \frac{\partial T}{\partial t}+u \frac{\partial T}{\partial x}+v \frac{\partial T}{\partial y}+w \frac{\partial T}{\partial z}-\frac{k_{x}}{\rho c_{p}} \frac{\partial^{2} T}{\partial x^{2}} \\
& -\frac{k_{y}}{\rho c_{p}} \frac{\partial^{2} T}{\partial y^{2}}-\frac{k_{z}}{\rho c_{p}} \frac{\partial^{2} T}{\partial z^{2}}=0
\end{aligned}
$$

considering $k_{x}, k_{y}$ e $k_{z}$ as thermal conductivity in the $x, y, z$-directions, respectively, $\rho$ as mass density and $c_{p}$ as heat capacity.

Rearranging the Eq. (1), taking $\alpha_{x}=\frac{k_{x}}{\rho c_{p}}$, $\alpha_{y}=\frac{k_{y}}{\rho c_{p}}$ and $\alpha_{z}=\frac{k_{z}}{\rho c_{p}}$ where $\alpha_{x}, \alpha_{y}$ and $\alpha_{z}$ is the thermal diffusivity in the $x, y, z$-directions, respectively, and using the Crank-Nicolson method to carry out the time discretization, we obtain:

$$
\begin{gathered}
\left(\frac{T_{i j k}^{n+1}-T_{i j k}^{n}}{\Delta t}\right)=\frac{1}{2}\left(\alpha_{x} \frac{\partial^{2} T}{\partial x^{2}}+\alpha_{y} \frac{\partial^{2} T}{\partial y^{2}}+\alpha_{z} \frac{\partial^{2} T}{\partial z^{2}}-u \frac{\partial T}{\partial x}\right. \\
\left.-v \frac{\partial T}{\partial y}-w \frac{\partial T}{\partial z}\right)_{i j k}^{n+1}+\frac{1}{2}\left(\alpha_{x} \frac{\partial^{2} T}{\partial x^{2}}+\alpha_{y} \frac{\partial^{2} T}{\partial y^{2}}+\alpha_{z} \frac{\partial^{2} T}{\partial z^{2}}\right. \\
\left.-u \frac{\partial T}{\partial x}-v \frac{\partial T}{\partial y}-w \frac{\partial T}{\partial z}\right)_{i j k}^{n} \\
\Rightarrow-\frac{1}{2}\left(\alpha_{x} \frac{\partial^{2} T_{i j k}^{n+1}}{\partial x^{2}}+\alpha_{y} \frac{\partial^{2} T_{i j k}^{n+1}}{\partial y^{2}}+\alpha_{z} \frac{\partial^{2} T_{i j}^{n+1}}{\partial z^{2}}\right.
\end{gathered}
$$

$\left.+u \frac{\partial T_{i j k}^{n+1}}{\partial x}+v \frac{\partial T_{i j k}^{n+1}}{\partial y}+w \frac{\partial T_{i j k}^{n+1}}{\partial z}\right)+\frac{T_{i j k}^{n+1}}{\Delta t}=G$

where

$G=\frac{1}{2}\left(\alpha_{x} \frac{\partial^{2} T_{i j k}^{n}}{\partial x^{2}}+\alpha_{y} \frac{\partial^{2} T_{i j k}^{n}}{\partial y^{2}}+\alpha_{z} \frac{\partial^{2} T_{i j}^{n}}{\partial z^{2}}-u \frac{\partial T_{i j k}^{n}}{\partial x}\right.$

$\left.-v \frac{\partial T_{i j k}^{n}}{\partial y}-w \frac{\partial T_{i j k}^{n}}{\partial z}\right)+\frac{T_{i j k}^{n}}{\Delta t}$.

In the applications 1 and 2 below, the initial value of the exact solution is taken as the initial condition, and boundary conditions are also specified by the above equation and change with time. However, for the applications 3 and 4, the conditions will be specified in the same case.

The following criteria will be used for the spatial discretization of the previous equation:

- For nodes with $\Delta x$ and $\Delta y$ distant from the boundary using the Central Difference Method with $\mathrm{O}\left(\Delta x^{2}\right)$, we have:

$$
\begin{gathered}
\left(-\frac{\alpha_{z}}{2 \Delta z^{2}}-\frac{w}{4 \Delta z}\right) T_{i, j, k-1}^{n+1}+\left(-\frac{\alpha_{y}}{2 \Delta y^{2}}-\frac{v}{4 \Delta y}\right) T_{i, j-1, k}^{n+1} \\
+\left(-\frac{\alpha_{x}}{2 \Delta x^{2}}-\frac{u}{4 \Delta x}\right) T_{i-1, j, k}^{n+1}+\left(\frac{\alpha_{x}}{\Delta x^{2}}+\frac{\alpha_{y}}{\Delta y^{2}}+\frac{\alpha_{z}}{\Delta z^{2}}+\frac{1}{\Delta t}\right) T_{i j k}^{n+1} \\
+\left(-\frac{\alpha_{x}}{2 \Delta x^{2}}+\frac{u}{4 \Delta x}\right) T_{i+1, j, k}^{n+1}+\left(-\frac{\alpha_{y}}{2 \Delta y^{2}}+\frac{v}{4 \Delta y}\right) T_{i, j+1, k}^{n+1} \\
+\left(-\frac{\alpha_{z}}{2 \Delta z^{2}}+\frac{w}{4 \Delta z}\right) T_{i, j, k+1}^{n+1}=G
\end{gathered}
$$

where

$$
\begin{aligned}
G & =\frac{\alpha_{x}}{2}\left(\frac{T_{i+1, j, k}^{n}-2 T_{i j k}^{n}+T_{i-1, j, k}^{n}}{\Delta x^{2}}\right) \\
+ & \frac{\alpha_{y}}{2}\left(\frac{T_{i, j+1, k}^{n}-2 T_{i j k}^{n}+T_{i, j-1, k}^{n}}{\Delta y^{2}}\right) \\
+ & \frac{\alpha_{z}}{2}\left(\frac{T_{i, j, k+1}^{n}-2 T_{i j k}^{n}+T_{i, j, k-1}^{n}}{\Delta z^{2}}\right) \\
& -\frac{u}{2}\left(\frac{T_{i+1, j, k}^{n}-T_{i-1, j, k}^{n}}{2 \Delta x}\right)-\frac{v}{2}\left(\frac{T_{i, j+1, k}^{n}-T_{i, j-1, k}^{n}}{2 \Delta y}\right) \\
& -\frac{w}{2}\left(\frac{T_{i, j, k+1}^{n}-T_{i, j, k-1}^{n}}{2 \Delta z}\right)+\frac{1}{\Delta t} T_{i j k}^{n} .
\end{aligned}
$$

- Now, for the other nodes, using the Central Difference Method with $\mathrm{O}\left(\Delta x^{4}\right)$, we have: 
$\left(\frac{\alpha_{x}}{24 \Delta z^{2}}+\frac{w}{24 \Delta z}\right) T_{i, j, k-2}^{n+1}+\left(-\frac{2 \alpha_{z}}{3 \Delta z^{2}}-\frac{2 w}{3 \Delta z}\right) T_{i, j, k-1}^{n+1}$

$+\left(\frac{\alpha_{y}}{24 \Delta y^{2}}+\frac{v}{24 \Delta y}\right) T_{i, j-2, k}^{n+1}+\left(-\frac{2 \alpha_{y}}{3 \Delta y^{2}}-\frac{v}{3 \Delta y}\right) T_{i, j-1, k}^{n+1}$

$+\left(\frac{\alpha_{x}}{24 \Delta x^{2}}+\frac{u}{24 \Delta x}\right) T_{i-2, j, k}^{n+1}+\left(-\frac{2 \alpha_{x}}{3 \Delta x^{2}}-\frac{u}{3 \Delta x}\right) T_{i-1, j, k}^{n+1}$

$+\left(\frac{1,25 \alpha_{x}}{\Delta x^{2}}+\frac{1,25 \alpha_{y}}{\Delta y^{2}}+\frac{1,25 \alpha_{z}}{\Delta z^{2}}+\frac{1}{\Delta t}\right) T_{i j k}^{n+1}$

$+\left(-\frac{2 \alpha_{x}}{3 \Delta x^{2}}+\frac{u}{3 \Delta x}\right) T_{i+1, j, k}^{n+1}+\left(\frac{\alpha_{x}}{24 \Delta x^{2}}-\frac{u}{24 \Delta x}\right) T_{i+2, j, k}^{n+1}$

$+\left(-\frac{2 \alpha_{y}}{3 \Delta y^{2}}+\frac{v}{3 \Delta y}\right) T_{i, j+1, k}^{n+1}+\left(\frac{\alpha_{y}}{24 \Delta y^{2}}-\frac{v}{24 \Delta y}\right) T_{i, j+2, k}^{n+1}$

$+\left(-\frac{2 \alpha_{z}}{3 \Delta z^{2}}+\frac{w}{3 \Delta z}\right) T_{i, j, k+1}^{n+1}+\left(\frac{\alpha_{z}}{24 \Delta z^{2}}-\frac{w}{24 \Delta z}\right) T_{i, j, k+2}^{n+1}=G$

where

$G=\frac{\alpha_{x}}{2}\left(\frac{-T_{i+2, j, k}^{n}+16 T_{i+1, j, k}^{n}-30 T_{i j k}^{n}+16 T_{i-1, j, k}^{n}-T_{i-2, j, k}^{n}}{12 \Delta x^{2}}\right)$

$+\frac{\alpha_{y}}{2}\left(\frac{-T_{i, j+2, k}^{n}+16 T_{i, j+1, k}^{n}-30 T_{i j k}^{n}+16 T_{i, j-1, k}^{n}-T_{i, j-2, k}^{n}}{12 \Delta y^{2}}\right)$

$+\frac{\alpha_{z}}{2}\left(\frac{-T_{i, j, k+2}^{n}+16 T_{i, j, k+1}^{n}-30 T_{i j k}^{n}+16 T_{i, j, k-1}^{n}-T_{i, j, k-2}^{n}}{12 \Delta z^{2}}\right)$

$-\frac{u}{2}\left(\frac{-T_{i+2, j, k}^{n}+8 T_{i+1, j, k}^{n}-8 T_{i-1, j, k}^{n}+T_{i-2, j, k}^{n}}{12 \Delta x}\right)$

$-\frac{v}{2}\left(\frac{-T_{i, j+2, k}^{n}+8 T_{i, j+1, k}^{n}-8 T_{i, j-1, k}^{n}-T_{i, j-2, k}^{n}}{12 \Delta y}\right)$

$-\frac{w}{2}\left(\frac{-T_{i, j, k+2}^{n}+8 T_{i, j, k+1}^{n}-8 T_{i, j, k-1}^{n}-T_{i, j, k-2}^{n}}{12 \Lambda z}\right)+\frac{1}{\Delta t} T_{i j k}^{n}$.

\section{RESULTS AND DISCUSSION}

The linear system generated by governing equation and the boundary conditions were solved via a Gauss-Seidel method, considering the maximum error for stopping criterion for the Gauss-Seidel of 10-8. All computations were run on a Intel Core i7/2.4G private computer using double precision arithmetic.

In the applications 1 and 2 , the computational domain is $0 \leq x, y, z \leq 1$ with $t=1$ and was used a uniform grid $\Delta x=\Delta y=\Delta z$ and was compared accuracy under the $L_{\infty}$ norm errors, which is the maximum error in the entire domain, given by $\|e\|_{\infty}=\left|T_{(\text {num })}-T_{(a n)}\right|$, where $T_{(\text {num })}$ and $T_{(a n)}$ is the result of the numerical and analytical solution, respectively. Now, in the application 3, we used the
$L_{2}$ norm, defined by $\|\varepsilon\|_{2}=\left[\left(\sum_{i=1}^{\text {Nnost }} e_{i}^{2}\right) / \text { Nnost }\right]^{1 / 2}$, where $N_{\text {nost }}$ is the total number of nodes in the mesh and $e_{i}=\left|T_{(\text {num })_{i}}-T_{(a n)_{i}}\right|$.

\section{Application 1}

In this application,we considered a pure diffusive case according to the equation $\frac{\partial T}{\partial t}=\frac{1}{3}\left(\frac{\partial^{2} T}{\partial x^{2}}+\frac{\partial^{2} T}{\partial y^{2}}+\frac{\partial^{2} T}{\partial z^{2}}\right)$ with an analytical solution given by $T(x, y, z, t)=e^{(t+x+y+z)}$. Table 1 shows the comparison between the present results and the analytical solution, which made an analysis of the $L_{\infty}$ norm of error in the numerical solution of $T(x, y, z, t)$. The CPU time, according to the configurations mentioned above, is listed in Table 2 .

Table 1. $L_{\infty}$ norm of the error committed in $T$ -

Application 1.

\begin{tabular}{|c|c|c|c|c|}
\hline \multirow{2}{*}{$\Delta t$} & \multicolumn{4}{|c|}{$\Delta x=\Delta y=\Delta z$} \\
\cline { 2 - 5 } & $\mathbf{1 / 1 0}$ & $\mathbf{1 / 2 0}$ & $\mathbf{1 / 4 0}$ & $\mathbf{1 / 5 0}$ \\
\hline 0.1 & $2.18 \mathrm{E}-03$ & $1.81 \mathrm{E}-03$ & $1.79 \mathrm{E}-03$ & $1.79 \mathrm{E}-03$ \\
\hline 0.05 & $9.29 \mathrm{E}-04$ & $4.76 \mathrm{E}-04$ & $4.50 \mathrm{E}-04$ & $4.48 \mathrm{E}-04$ \\
\hline 0.01 & $6.25 \mathrm{E}-04$ & $6.27 \mathrm{E}-05$ & $1.91 \mathrm{E}-05$ & $1.74 \mathrm{E}-05$ \\
\hline 0.005 & $6.16 \mathrm{E}-04$ & $5.74 \mathrm{E}-05$ & $6.13 \mathrm{E}-06$ & $4.20 \mathrm{E}-06$ \\
\hline 0.001 & $6.13 \mathrm{E}-04$ & $5.60 \mathrm{E}-05$ & $4.40 \mathrm{E}-06$ & $1.90 \mathrm{E}-06$ \\
\hline
\end{tabular}

In Table 1 is noted that the numerical results for some refined meshes was obtained a precision of at six decimal places, which is considered suitable for engineering.

Table 2. Computational time $(s)$ - Application 1.

\begin{tabular}{|c|c|c|c|c|}
\hline \multirow{2}{*}{$\Delta t$} & \multicolumn{4}{|c|}{$\Delta x=\Delta y=\Delta z$} \\
\cline { 2 - 5 } & $\mathbf{1 / 1 0}$ & $\mathbf{1 / 2 0}$ & $\mathbf{1 / 4 0}$ & $\mathbf{1 / 5 0}$ \\
\hline 0.1 & 0.859 & 12.266 & 291.594 & 856.844 \\
\hline 0.05 & 1.125 & 14.156 & 334.063 & 1019.172 \\
\hline 0.01 & 2.219 & 19.203 & 439.656 & 1269.281 \\
\hline 0.005 & 2.734 & 24.485 & 453.406 & 1494.672 \\
\hline 0.001 & 8.844 & 52.343 & 709.250 & 2009.328 \\
\hline
\end{tabular}

\section{Application 2}

Now, this is a advective-diffusive case according to the governing equation $\frac{\partial T}{\partial t}+2 \frac{\partial T}{\partial x}=\frac{\partial^{2} T}{\partial x^{2}}+\frac{\partial^{2} T}{\partial y^{2}}+\frac{\partial^{2} T}{\partial z^{2}} \quad$ which analytical solution is $T(x, y, z, t)=e^{(t+x+y+z)}$. Similarly to the previous application, the Table 3 and 4, show, respectively, the comparison between the present results and the analytical solution, which made an 
analysis of the $L_{\infty}$ norm of error in the numerical solution of $T(x, y, z, t)$ and the CPU time.

Table 3. $L_{\infty}$ norm of the error committed in $T$ Application 2.

\begin{tabular}{|c|c|c|c|c|}
\hline \multirow{2}{*}{$\Delta t$} & \multicolumn{4}{|c|}{$\Delta \boldsymbol{x}=\Delta y=\Delta z$} \\
\cline { 2 - 5 } & $\mathbf{1 / 1 0}$ & $\mathbf{1 / 2 0}$ & $\mathbf{1 / 4 0}$ & $\mathbf{1 / 5 0}$ \\
\hline 0.1 & $4.92 \mathrm{E}-04$ & $6.27 \mathrm{E}-04$ & $6.35 \mathrm{E}-04$ & $6.36 \mathrm{E}-04$ \\
\hline 0.05 & $1.36 \mathrm{E}-04$ & $1.49 \mathrm{E}-04$ & $1.57 \mathrm{E}-04$ & $1.57 \mathrm{E}-04$ \\
\hline 0.01 & $2.11 \mathrm{E}-04$ & $1.73 \mathrm{E}-05$ & $4.96 \mathrm{E}-06$ & $4.93 \mathrm{E}-06$ \\
\hline 0.005 & $2.13 \mathrm{E}-04$ & $1.86 \mathrm{E}-05$ & $1.30 \mathrm{E}-06$ & $5.20 \mathrm{E}-07$ \\
\hline 0.001 & $2.14 \mathrm{E}-04$ & $1.91 \mathrm{E}-05$ & $1.49 \mathrm{E}-06$ & $1.48 \mathrm{E}-06$ \\
\hline
\end{tabular}

Table 4. Computational time $(s)$ - Application 2.

\begin{tabular}{|c|c|c|c|c|}
\hline \multirow{2}{*}{$\Delta \boldsymbol{t}$} & \multicolumn{4}{|c|}{$\Delta \boldsymbol{x}=\Delta \boldsymbol{y}=\Delta \boldsymbol{z}$} \\
\cline { 2 - 5 } & $\mathbf{1 / 1 0}$ & $\mathbf{1 / 2 0}$ & $\mathbf{1 / 4 0}$ & $\mathbf{1 / 5 0}$ \\
\hline 0.1 & 1.375 & 18.875 & 492.563 & 1547.500 \\
\hline 0.05 & 1.906 & 27.766 & 778.922 & 2222.391 \\
\hline 0.01 & 3.031 & 40.454 & 1136.250 & 3210.422 \\
\hline 0.005 & 4.954 & 46.297 & 1273.188 & 3604.047 \\
\hline 0.001 & 11.562 & 89.500 & 1535.500 & 4204.719 \\
\hline
\end{tabular}

\section{Application 3}

In this application, was considered an advectivediffusive case with the governing equation $\frac{\partial T}{\partial t}+0,8\left(\frac{\partial T}{\partial x}+\frac{\partial T}{\partial y}+\frac{\partial T}{\partial z}\right)=0,01\left(\frac{\partial^{2} T}{\partial x^{2}}+\frac{\partial^{2} T}{\partial y^{2}}+\frac{\partial^{2} T}{\partial z^{2}}\right)$ with the following analytical solution given by [Ge, Tian and Zhang (2013); Karaa (2006)]:

$$
\begin{aligned}
& T(x, y, z, t)=(4 t+1)^{-3 / 2} \exp \left(-\frac{1}{0,01(4 t+1)}\right. \\
& \left.\left((x-0,8 t-0,5)^{2}+(y-0,8 t-0,5)^{2}+(z-0,8 t-0,5)^{2}\right)\right)
\end{aligned}
$$

The Dirichlet boundary and initial conditions are directly taken from this analytical solution. The computational domain is $0 \leq x, y, z \leq 2$ and $t=1.25$ and the regular mesh with $h=\Delta x=\Delta y=\Delta z$ was used.We adopt $h=0.025$ so as to compare the results obtained in this work the ones presented by [Ge, Tian and Zhang (2013)] in which three methodologies were implemented for the solution of convectiondiffusion equation, all based on the alternating direction implicit method. We may note from Table 5 , the results of this study in comparison with the literature, have an equal or higher accuracy for the different values of $\lambda$. Even considering a coarse mesh $(h=0.05)$, the methodology proposed here achieves a precision equivalent to those obtained by other authors with a very refined mesh.

\begin{tabular}{|c|c|c|c|c|c|}
\hline \multirow[b]{2}{*}{$\lambda$} & \multicolumn{4}{|c|}{$h=0.025$} & \multirow{2}{*}{$\begin{array}{c}h=0.05 \\
\begin{array}{c}\text { Present } \\
\text { work }\end{array} \\
\end{array}$} \\
\hline & $\begin{array}{c}\text { Douglas-Gunn } \\
\text { ADI scheme [Ge, } \\
\text { Tian and Zhang } \\
\text { (2013)] } \\
\end{array}$ & $\begin{array}{l}\text { Karaa's ADI } \\
\text { scheme [Ge, Tian } \\
\text { and Zhang } \\
\text { (2013)] }\end{array}$ & $\begin{array}{c}\text { Exponential high order } \\
\text { compact ADI scheme } \\
\text { [Ge, Tian and Zhang } \\
(2013)]\end{array}$ & Present work & \\
\hline 5 & $5.599 \mathrm{E}-04$ & $5.184 \mathrm{E}-05$ & $5.266 \mathrm{E}-05$ & $5.261 \mathrm{E}-06$ & 4.900E-05 \\
\hline 10 & $5.764 \mathrm{E}-04$ & $5.268 \mathrm{E}-05$ & $5.309 \mathrm{E}-05$ & $1.353 \mathrm{E}-05$ & $5.431 \mathrm{E}-05$ \\
\hline 20 & 5.991E-04 & $6.978 \mathrm{E}-05$ & $6.674 \mathrm{E}-05$ & 4.845E-05 & $8.152 \mathrm{E}-05$ \\
\hline 40 & $7.329 \mathrm{E}-04$ & $2.035 \mathrm{E}-04$ & $1.858 \mathrm{E}-04$ & $1.907 \mathrm{E}-04$ & $2.413 \mathrm{E}-04$ \\
\hline
\end{tabular}

Table 5. $L_{2}$ error with $h=0.025$ and $h=0.05, \Delta t=\lambda h^{2}, t=1.25$ and different $\lambda$ - Application 3 .

\begin{tabular}{|c|c|c|c|c|c|}
\hline \multirow[b]{2}{*}{$\lambda$} & \multicolumn{4}{|c|}{$h=0.025$} & \multirow{2}{*}{$\begin{array}{c}\qquad \boldsymbol{h}=\mathbf{0 . 0 5} \\
\text { Present work }\end{array}$} \\
\hline & $\begin{array}{c}\text { Douglas-Gunn } \\
\text { ADI scheme [Ge, } \\
\text { Tian and Zhang } \\
(2013)]\end{array}$ & $\begin{array}{c}\text { Karaa's ADI } \\
\text { scheme [Ge, } \\
\text { Tian and Zhang } \\
(2013)]\end{array}$ & $\begin{array}{c}\text { Exponential high order } \\
\text { compact ADI scheme } \\
\text { [Ge, Tian and Zhang } \\
(2013)]\end{array}$ & Present work & \\
\hline 5 & 762.04 & 1081.65 & 829.45 & 897.953 & 121.344 \\
\hline 10 & 379.87 & 551.39 & 412.14 & 476.562 & 72.203 \\
\hline 20 & 188.42 & 280.35 & 207.96 & 316.64 & 41.875 \\
\hline 40 & 97.45 & 142.28 & 104.11 & 138.891 & 28.36 \\
\hline
\end{tabular}

Table 6. Computational time $(s)$ - Application 3. 


\section{Application 4}

In this case, we considered the equation $\frac{\partial T}{\partial t}+w \frac{\partial T}{\partial z}-\frac{k}{\rho c_{p}}\left(\frac{\partial^{2} T}{\partial x^{2}}+\frac{\partial^{2} T}{\partial y^{2}}+\frac{\partial^{2} T}{\partial z^{2}}\right)=0$.

Considering $T_{\text {air }}=300 \mathrm{~K}$, we adopt the following thermophysical properties [Incropera and DeWitt (1996)]: $\rho=1.1614 \mathrm{~kg} / \mathrm{m}^{3}, \quad c_{p}=1007 \mathrm{~J} / \mathrm{kg} . \mathrm{K}$, $k=0.0263 \mathrm{~W} / \mathrm{m} . \mathrm{K}$ for mass density, heat capacity and thermal conductivity, respectively. Thus, $\frac{k}{\rho c_{p}} \cong 0.00022488$. A parabolic velocity profile, representing a fully developed laminar flow was defined by [Romão and Moura (2012)]: $w(x, y, z, t)=\frac{16 U_{\max }}{L_{x} \cdot L_{y}}\left(-\frac{x^{2}}{L_{x}}+x\right)\left(-\frac{y^{2}}{L_{y}}+y\right)$, wh ere $U_{\max }$ is the top speed on the flow centerline.

We assume air at atmospheric pressure and temperature $300 \mathrm{~K}$, flowing into a rectangular channel with dimensions $L_{x} \times L_{y} \times L_{z}$, considering the following boundary conditions, according the Fig. 1 :

- in the plane $X Y$ with $z=0: T=T_{\text {inlet }}$, being $T_{\text {inlet }}$ the inlet temperature in the channel;

- in the plane $X Y$ with $z=L_{z}: \frac{\partial T}{\partial z}=0$;

- in the plane $Y Z$ with $x=0$ or $x=L_{x}: \frac{\partial T}{\partial x}=0$;

- in the plane $X Z$ with $y=0: \frac{\partial T}{\partial y}=0$;

- in the plane $X Z$ with $y=L_{y}: T=T_{c}$, being $T_{c}$ the cooling temperature of fluid.

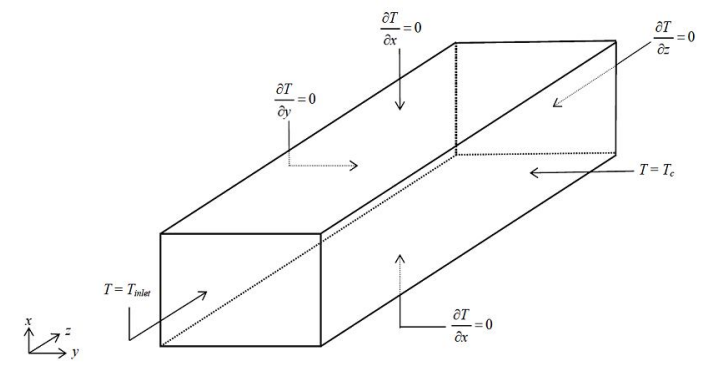

Figure 1. Computational domain and boundary conditions - Application 4.

Considering an inlet temperature of $30^{\circ} \mathrm{C}$, our objective is the cooling of air at an average temperature of $15^{\circ} \mathrm{C}$ in the outlet section of the channel. Taking $L_{x}=L_{y}=0.2 \mathrm{~m} ; L_{z}=1 \mathrm{~m}$ and $L_{t}=100 \mathrm{~s}$ and considering a mesh refinement $\Delta x=L_{x} / 40, \Delta y=L_{y} / 40, \Delta z=L_{z} / 100$ and $\Delta t=L_{t} / 500$. By varying the values of the cooling temperature $\left(T_{c}\right)$ at the entrance, the results of average temperature in the output section of the channel, here denoted by $T_{a}$, are shown in Table 7, considering the order of accuracy with two decimal places.

In Table 7 , we note that as the cooling temperature decreases by $1{ }^{\circ} \mathrm{C}$, the average temperature of the output section is reduced to 0.16 ${ }^{\circ} \mathrm{C}$. Thus, in order to achieve a mean temperature of $15{ }^{\circ} \mathrm{C}$ in the output section will require a cooling temperature of approximately $-64.25^{\circ} \mathrm{C}$.

Table 7. Results of $T_{a}$ at the outlet section of the channel depending on thecooling temperature in the entrance $\left(T_{c}\right)$, considering $\Delta x=L_{x} / 200, \Delta y=L_{y} / 10$, $\Delta z=L_{z} / 100$ and $\Delta t=t / 500$.

\begin{tabular}{|c|c|}
\hline$T_{c}\left({ }^{\mathbf{0}} \mathbf{C}\right)$ & $T_{a}\left({ }^{\mathbf{}} \mathbf{C}\right)$ \\
\hline 10 & 26.78 \\
\hline 9 & 26.62 \\
\hline 8 & 26.46 \\
\hline 7 & 26.30 \\
\hline 6 & 26.14 \\
\hline 5 & 25.98 \\
\hline 4 & 25.82 \\
\hline 3 & 25.66 \\
\hline 2 & 25.50 \\
\hline 1 & 25.34 \\
\hline 0 & 25.18 \\
\hline-1 & 25.02 \\
\hline-2 & 24.96 \\
\hline-3 & 24.80 \\
\hline
\end{tabular}

Two other strategies for the expected average temperature is achieved on the output variation were the length and size of the inlet section of the channel. Thus, taking $L_{x}=L_{y}=0.2 \mathrm{~m}$ and varying $L_{z}$ and $L_{t}=100$ s,considering a mesh refinement $\Delta x=L_{x} / 40, \Delta y=L_{y} / 40, \Delta z=0.01$ and $\Delta t=L_{t} / 500$, with $T_{c}=1^{\circ} \mathrm{C}$, the obtained numerical values shown in Table 8. Note, that it was necessary length $z=3 \mathrm{~m}$ so that the temperature of $23.35^{\circ} \mathrm{C}$ was reached. Likewise, to reach $22.22^{\circ} \mathrm{C}$, it was necessary to $z=6 \mathrm{~m}$, indicating the relation between the variation of the channel length and cooling the same. It can be noted clearly, that for the conditions in this case, the variation of the channel length, the average temperature tends to stagnate at a value close to $22{ }^{\circ} \mathrm{C}$.

Table 8. Results of $T_{a}$ at the outlet section of the channel depending on the variation of the channel length, considering $\Delta x=L_{x} / 40, \Delta y=L_{y} / 40, \Delta z=0.01$ and $\Delta t=L_{t} / 500$.

\begin{tabular}{|c|c|}
\hline$L_{z}(\mathrm{~m})$ & $T_{a}\left({ }^{\mathbf{}} \mathbf{C}\right)$ \\
\hline 1.0 & 25.34 \\
\hline 1.5 & 24.67 \\
\hline 2.0 & 24.14 \\
\hline 2.5 & 23.71 \\
\hline 3.0 & 23.35 \\
\hline 3.5 & 23.06 \\
\hline 4.0 & 22.81 \\
\hline
\end{tabular}




\begin{tabular}{|l|l|}
\hline 4.5 & 22.61 \\
\hline 5.0 & 22.45 \\
\hline 5.5 & 22.32 \\
\hline 6.0 & 22.22 \\
\hline 6.5 & 22.16 \\
\hline
\end{tabular}

Considering, now, the variation of the inlet section of the channel and taking $L_{x}=L_{y}$; varying $L_{z}=$ $1 \mathrm{~m}$ and $L_{t}=100$ sand considering a mesh refinement $\Delta x=\Delta y=0.005, \Delta z=L_{z} / 100$ and $\Delta t=L_{t} / 500$, with $T_{c}=1^{\circ} \mathrm{C}$, we obtained the values shown in Table 9.It can be noted that for $L_{z}=1 \mathrm{~m}, L_{x}=L_{y}=0.1 \mathrm{~m}$, $T_{c}=1^{\circ} \mathrm{C}$ and $L_{t}=100 \mathrm{~s}$ was achieved $T_{a} \cong 22.45^{\circ} \mathrm{C}$. However, modifying $L_{t}=200 \mathrm{~s}$ or $L_{t}=300 \mathrm{~s}$, the results in the output section have not changed, which proves the steady state temperature distribution.

Another test was carried out by taking $L_{z}=5 \mathrm{~m}$, $\Delta z=L_{z} / 500, L_{x}=L_{y}=0.1 \mathrm{~m}, \Delta x=\Delta y=L_{x} / 20$, $L_{t}=100 \mathrm{~s}, \Delta t=L_{t} / 500$ to $T_{c}=1^{\circ} \mathrm{C}$. The results obtained in this case are shown in Fig. 2. It can be noted that the mean temperature of $15^{\circ} \mathrm{C}$ was achieved in 100s.

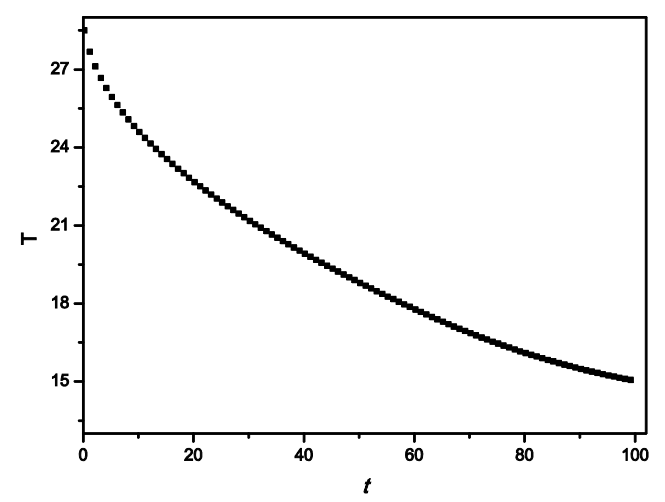

Figure 2. Results of the average temperature in the outlet section of the channel depending of time Application 4.

Table 9. Results of $T_{a}$ at the outlet section of the channeldepending on the variation of the channel length,considering $\Delta x=L_{x} / 40, \Delta y=L_{y} / 40, \Delta z=0.01$ and $\Delta t=L_{t} / 500$.

\begin{tabular}{|c|c|}
\hline$\Delta x=\Delta y$ & $T_{\mathrm{a}}\left({ }^{\circ} \mathrm{C}\right)$ \\
\hline 0.20 & 25.98 \\
\hline 0.19 & 25.16 \\
\hline 0.18 & 24.98 \\
\hline 0.17 & 24.77 \\
\hline 0.16 & 24.54 \\
\hline 0.15 & 24.28 \\
\hline 0.14 & 23.98 \\
\hline 0.13 & 23.65 \\
\hline 0.12 & 23.26 \\
\hline 0.11 & 22.80 \\
\hline 0.10 & 22.25 \\
\hline
\end{tabular}

\section{CONCLUSIONS}

In this paper, we propose a high-order Finite Difference Method for three-dimensional heat transfer equation. Numerical examples show that the method can be used to simulate the numerical solution of the equation, with emphasis on the application involving heat exchange in a rectangular channel. By observing the detailed comparison of numerical and analytical results, it is convinced that the proposed scheme is very simple, stable and accurate for the solutions of the heat transfer equation.

\section{Acknowledgements}

We acknowledged the support from the National Council of Scientific Development and Technology, CNPq, Brazil (Proc. 500382/2011-5) and Mato Grosso Research Foundation, Fapemat, Brazil (Proc. 292470/2010).

\section{REFERENCES}

Dehghan, M., 2004, Numerical Solution of the Three-dimensional Advection-Diffusion Equation, Applied Mathematics and Computation, Vol. 150, pp. 5-19.

Fletcher, J. D., 1983, Generating Exact Solutions of the Two-dimensional Burgers' Equations, International Journal for Numerical Methods in Fluids, Vol. 3, pp. 213-316.

Forsythe, G. E., and Wasow, W. R., 2013, Finite Difference Methods for Partial Differential Equations, Literary Licensing.

Ge, Y., Tian, Z. F., and Zhang, J., 2013, An Exponential High-Order Compact ADI method for 3D Unsteady Convection-Diffusion Problems, Numerical Methods for Partial Differential Equations, Vol. 29, pp. 186-205.

Hao, X. H., and Ju, Y. L., 2011, Simulation and Analysis on the Flow Field of the Low Temperature Mini-Type Cold Store, Heat Mass Transfer, Vol. 47, pp. 771-775.

Incropera F. P., and DeWitt, D. P., 1996, Fundamentals of Heat and Mass Transfer, 4th ed., John Wiley \& Sons.

Islam, S., Sarler, B., Vertnik, R., and Kosec, G., 2012, Radial Basis Function Collocation Method for the Numerical Solution of the Two-dimensional Transient Nonlinear Coupled Burgers Equations, Applied Mathematical Modelling, Vol. 36, pp. 11481160.

Karaa, S., 2006, A High-Order Compact ADI Method for Solving Three-Dimensional Unsteady Convection-Diffusion Problems,Numerical Methods for Partial Differential Equations, Vol. 22, pp. 983993.

Liu, J. C., and Hou, G. L., 2011, Numerical Solutions of the Space and Time Fractional Coupled Burgers Equations by Generalized Differential 
Transform Method, Applied Mathematics and Computation, Vol. 217, pp. 7001-7008.

Malalasekera, W., and Versteeg, H., 2007, An Introduction to Computational Fluid Dynamics: The Finite Volume Method, 2nd ed., Pearson.

Mittal, R. C., and Jiwari, R., 2009, Differential Quadrature Method for Two-dimensional Burgers' Equations, International Journal for Computational Methods in Engineering Science and Mechanics, Vol. 10, pp. 450-459.

Morton, K. W., and Mayers D. F., 1994, Numerical Solution of Partial Differential Equations. Cambridge University Press.

Prieto, U., Benito, J. J., Muñoz, J. B., and Corvinos, L.G., 2011, Application of the Generalized Finite Difference Method to Solve the AdvectionDiffusion Equation, Journal of Computational and Applied Mathematics., Vol. 235, pp. 1849-1855.

Roberts, S. M., and Shipman, J. S., 1972, Two Point Boundary Value Problems: Shooting Methods. American Elsevier.

Romão, E. C., and Moura, L. F. M., 2012, Galerkin and Least Squares Methods to Solve a 3D Convection Diffusion Reaction Equation with Variable Coefficients, Numerical Heat Transfer, Part A: Applications, Vol. 61, pp. 669-698.

Smale, N. J., Moureh, J., and Cortella, G., 2006, A Review of Numerical Models of Airflow in Refrigerated Food Applications, International Journal of Refrigeration, Vol. 29, pp. 911-930.

Thomas, J. W., 1995, Numerical Partial Differential Equations: Finite Difference Methods. Springer-Verlag.

Thongmoon, M., Mckibbin, R., Tangmanee, S., 2007, Numerical Solution of a 3-D AdvectionDispersion Model for Pollutant Transport,Thai Journal of Mathematics, Vol. 5, pp. 91-108.

Wazwaz, A. M., 2001, The Numerical Solution of Sixth Order Boundary Value Problems by the Modified Decomposition Method, Applied Mathematics and Computation, Vol. 18, pp. 311-325.

Welty, J. R., Wilson, C. E., and Rorrer, G. L., 2001, Fundamental of Heat and Mass Transfer, 4th ed., Wiley.

Zhu, H., Shu, H., and Ding, M., 2010, Numerical Solutions of Two-Dimensional Burgers' Equations by Discrete Adomian Decomposition Method, Computers \& Mathematics with Applications, Vol. 60, pp. 840-848.

Zienkiewicz, O. C., Taylor, R. L., and Nithiarasu, P., 2013, The Finite Element Method for Fluid Dynamics, 7th ed., Butterworth-Heinemann. 